\title{
What to do when there is no standard of care: A brief review of treatment options for glioblastoma in children
}

In this issue of Journal of Neuroscience in Rural Practice, Jain et al. show us the tragic case of a 5-year-old girl with a glioblastoma that recurred with leptomeningeal dissemination 8 months after resection and adjuvant radiation and chemotherapy. ${ }^{[1]}$ She died 6 weeks later. We would like to take this opportunity to discuss the recent advances in the treatment of glioblastoma in the pediatric population.

High grade gliomas, including glioblastomas, remain one of the great clinical enigmas in the practice of neuro-oncology. While we have learned a great deal over the past several decades, their prognosis remains dismal. The standard of care in adults is maximal safe surgical resection, followed by concurrent local radiation and the alkylating agent temozolomide, based on the landmark study of Stupp et al. ${ }^{[2]}$ Temozolomide was not beneficial in the pediatric population however, producing no survival advantage over a nitrosourea based chemotherapy regimen from the 1980's in the phase II prospective Children's Oncology Group trial ACNS0126 of concurrent temozolomide with radiation therapy, followed by temozolomide..$^{[3]}$ The reason behind the negative outcome in this regimen was speculated to be to be due to differences in molecular between adult and pediatric glioblastomas. While the majority of adult glioblastomas harbor mutations in PTEN and overexpress EGFR, most children's tumors do not, ${ }^{[4]}$ suggesting that glioblastoma is a quite different entity in children compared to their adult counterparts.

While many molecular differences have been noted in pathologic studies between childhood and adult glioblastomas, only one has been shown to correlate

\begin{tabular}{|l|l|}
\hline \multicolumn{2}{|c|}{ Access this article online } \\
\hline Quick Response Code: & Website: \\
\hline & www.ruralneuropractice.com \\
\cline { 2 - 3 } & \\
\hline
\end{tabular}

strongly with outcome - MGMT overexpression. An overexpression of ${ }^{6} \mathrm{O}$-methylguanine-methyltransferase has been shown to directly correlate with response to alkylating agents, including temozolomide, in both children and adults. ${ }^{[5]}$ Subgroup analysis of the large prospective trial CCG-945 found that children with MGMT overexpressing gliomas had a 5-year progression free survival of $42.1 \%$, compared to only $8.3 \%$ in the children without MGMT overexpression. Unfortunately, only $11 \%$ of the malignant pediatric gliomas in this trial overexpressed MGMT. ${ }^{[6]}$ While temozolomide did not benefit the overall pediatric malignant glioma population, it may be very helpful for the minority of children with MGMT overexpressing tumors.

The current Children's Oncology Group trial ACNS0822 for glioblastoma in children is testing a number of radiosensitizing agents in the concurrent setting, and will then 'pick the winner' to be compared to radiation and concurrent temozolomide in a phase III trial. This trial will test 2 promising agents in the concurrent setting: Vorinostat, a histone deacetylase inhibitor that has been shown to modulate radiation response in a pre-clinical study ${ }^{[7]}$ and bevacizumab, a VEGF inhibitor that has been shown to be safe when given with radiation and to have efficacy in many tumor types in children. ${ }^{[8]} \mathrm{COG}$ ACNS0822 is expected to establish a standard of care by comparing the best adjuvant chemotherapy regimens head to head.

Once a child has progressed or recurred after an initial multimodality therapy, as the patient presented here did, there is, again, no standard therapy. There are several novel agents and strategies currently being tested in children. Innovative strategies being tested or in preparation are integrin inhibition with celingitide (recently closed children's oncology group trial), immunotherapy with a dendritic cell vaccine, ${ }^{[9]}$ and novel anti-angiogenic agents to block the actions of VEGF (pediatric brain tumor consortium trial 020). While these 3 methods have not yet proceeded to phase III trials, each is being tested systematically with promising pre-clinical and safety data. 
While much progress has been made in understanding the molecular characteristics of glioblastoma, in both children and adults, this knowledge has not yet translated to success in the clinic. Even in adults, where the standard of care for glioblastoma in the upfront setting is firmly in place, there is no standard for recurrent or disseminated disease. In children, however, there is no established standard of care in either the upfront or recurrent / disseminated setting. Without patient entry into prospective clinical trials, these standards will never be established, and we will continue to experience the frustration that we feel today when presented with a patient like this. Therefore, we recommend that when a practitioner encounters a difficult and rare case such as this one, consultation with or referral to an academic center with a multimodality specialty team be made. In many cases, there will be clinical trials both in the newly diagnosed and recurrent or progressive setting available that can offer both hope to the patient and family and progress in our fight against devastating diseases.

$$
\begin{array}{r}
\text { Jacob G Scott, Robert S Lavey } \\
\begin{array}{r}
\text { Department of Radiation Oncology, H. Lee Moffitt Cancer Center } \\
\text { and Research Institute, Tampa, FL, USA }
\end{array} \\
\text { Address for correspondence: } \\
\text { Dr. Jacob Scott, } \\
\text { Department of Radiation Oncology, H. Lee Moffi tt Cancer Center } \\
\text { and Research Institute, Tampa, FL 33612, Tampa-USA. } \\
\text { E-mail: jacob.scott@moffi tt.org }
\end{array}
$$

\section{References}

1. Cugati G, Jain PK, Pande A, Symss NP, Vasudevan C, Ramamurthi R. Pediatric multifocal glioblastoma multiforme with fulminant course. J Neurosci Rural Pract 2012;3:174-7

2. Stupp R, Mason WP, van den Bent MJ, Weller M, Fisher B, Taphoorn MJ, et al. Radiotherapy plus concomitant and adjuvant temozolomide for glioblastoma. N Engl J Med 2005;352:987-96.

3. Cohen KJ, Heideman RL, Zhou T, Holmes EJ, Lavey RS, Bouffet E, et al. Temozolomide in the treatment of children with newly diagnosed diffuse intrinsic pontine gliomas: A report from the Children's Oncology Group. Neuro Oncol 2011;13:410-6.

4. Pollack IF, Hamilton RL, James CD, Finkelstein SD, Burnham J, Yates AJ, et al. Rarity of PTEN deletions and EGFR amplification in malignant gliomas of childhood: Results from the Children's Cancer Group 945 cohort. J Neurosurg 2006;105:418-24.

5. Hegi ME, Diserens AC, Gorlia T, Hamou MF, de Tribolet N, Weller $\mathrm{M}$, et al. MGMT gene silencing and benefit from temozolomide in glioblastoma. N Engl J Med 2005;352:997-1003.

6. Pollack IF, Hamilton RL, Sobol RW, Burnham J, Yates AJ, Holmes EJ, et al. O6-methylguanine-DNA methyltransferase expression strongly correlates with outcome in childhood malignant gliomas: Results from the CCG-945 Cohort. J Clin Oncol 2006;24:3431-7.

7. Chinnaivan P, Vallabhaneni G, Armstrong E, Huang SM, Harari PM. Modulation of radiation response by histone deacetylase inhibition. Int J Radiat Oncol Biol Phys 2005;62:223-9.

8. Glade Bender JL, Adamson PC, Reid JM, Xu L, Baruchel S, Shaked Y, et al. Phase I trial and pharmacokinetic study of bevacizumab in pediatric patients with refractory solid tumors: A Children's Oncology Group Study. J Clin Oncol 2008;26:399-405.

9. Ardon H, De Vleeschouwer S, Van Calenbergh F, Claes L, Kramm CM, Rutkowski $\mathrm{S}$, et al. Adjuvant dendritic cell-based tumour vaccination for children with malignant brain tumours. Pediatric Blood Cancer 2009;54:519-25.

How to cite this article: Scott JG, Lavey RS. What to do when there is no standard of care: A brief review of treatment options for glioblastoma in children. J Neurosci Rural Pract 2012;3:113-4.

\section{“QUICK RESPONSE CODE” LINK FOR FULL TEXT ARTICLES}

The journal issue has a unique new feature for reaching to the journal's website without typing a single letter. Each article on its first page has a "Quick Response Code". Using any mobile or other hand-held device with camera and GPRS/other internet source, one can reach to the full text of that particular article on the journal's website. Start a QR-code reading software (see list of free applications from http://tinyurl.com/yzlh2tc) and point the camera to the QR-code printed in the journal. It will automatically take you to the HTML full text of that article. One can also use a desktop or laptop with web camera for similar functionality. See http://tinyurl.com/2bw7fn3 or http://tinyurl.com/3ysr3me for the free applications. 